Trust plans to publish a quarterly journal which will carry abstracts from important world-wide literature as well as original papers on migraine. A symposium is planned for this autumn and the first international symposium will be held the following year.

\section{Project for Engineers}

THE Department of Education and Science launched a new magazine this week in its continuing attempt to interest senior school students in engineering as a career. Project will be published three times a year and 24,000 copies will be distributed to fifth and sixth forms throughout Britain. The engineering institutions are anxious to see the magazine succeed and are con. tributing articles and information but not money. The aim is to give a favourable impression of various types of engineering, the training required to become a qualified engineer, and the example of well-known engineering innovators-this first issue includes $\mathbf{a}$ profile of Dr. Barnes Wallis of the British Aircraft Corporation, whose ideas have not always been immediately accepted by the British Government but whose inventiveness and originality, according to the editor of Project, make him one of the outstanding engineers in Britain.

The magazine, a $£ 10,000$ glossy product, is produced by the Central Office of Information for what is known as the Publicity Working Party on Engineering Technology-the custodian of the British Government's hope that more students will be attracted into engineering and technology. Other projects have included a travelling exhibit for schools entitled "Technology Today", which has visited forty-five centres in the past 7 months, and an earlier publication, Engineering: a Creative Career, which attempts to present a broad spectrum of engineering problems, the routes to qualification beginning at both ' $O$ ' and ' $A$ ' levels, and typical university syllabuses. A national exhibition "Engineer's Day" will be held in London in the autumn. Although the new magazine is aimed for students, anyone interested can obtain copies from the Government bookshop or his newsagent at an annual cost of $15 s$.

\section{Safety Cars}

THE Road Research Laboratory of the Ministry of Transport has made a tentative bid to do for Britain what Mr. Ralph Nader seems to be doing for the United States. In its most recent report on Safety Cars (obtainable either from the Laboratory or the Ministry of Transport), Mr. G. Grime has applied Newton's Second Law to collisions between cars, and has been able to infer a great deal about the relative motion of cars and passengers in the fraction of a tenth of a second which seems usually to be required to crush the front of a car involved in a head-on collision by $60 \mathrm{~cm}$ or so. His general conclusion is that seat-belts are among the best means of protection, so that it is no surprise that Mrs. Barbara Castle, the Minister of Transport, should have announced a regulation that will in future require that cars should be equipped with anchorage points for seat-belts.

One of the simplest of Mr. Grime's conclusions is that passengers tend to come into contact with the vehicles which carry them only when the collision is almost at an end. In one calculation, for example, he found that by the time a human body had shot forward by $41 \mathrm{~cm}$ from the front seat to strike the instrument panel of a medium car in a head-on collision at $50 \mathrm{~km}$ per hour, the crushing of the front of the car would have only $0.5 \mathrm{~cm}$ to go. This means that the unlucky passenger would strike an essentially static object, and even the best padding on the instrument panel would entail a deceleration of $64 \mathrm{~g}$. A suitably padded and flexible steering-wheel might reduce the deceleration in these circumstances to $35 \mathrm{~g}$, but a seat-belt capable of a modicum of stretch could ensure that deceleration amounts to $17 \cdot 1 \mathrm{~g}$ in similar circumstances, and that the attendant forces are "applied in a controlled manner over a large and predetermined area". In all this the principle is that a person should be partially anchored to the car in which he rides, so that he can expect to benefit from the energy expenditure involved in crushing the front of the car.

$\mathrm{Mr}$. Grime is not optimistic about the prospects of greater safety by designing the front of a motor-car so as to minimize the consequences of collision. According to the calculations, seat-belts are always better. Mr. Grime does, however, conclude from American experience with would-be astronauts that it would be feasible to design seat-belts capable of decelerating people by something like $30 \mathrm{~g}$, compared with the $20 \mathrm{~g}$ which is now common. His dynamical calculations also persuaded him that there would be advantages in a design for a seat-belt capable of applying a greater force at the limit of its extension, and that the ideal is a situation in which seat-belt and seat are built as an integral whole. Finally, for those who will not wear seat-belts, there are some benefits to be won from crushable fittings on the instrument panel of a motorcar, especially if they can be so arranged as to help decelerating a passenger soon after the beginning of a collision.

\section{Put Out More Books}

WHEN Blackwells first opened their doors and started selling books in Oxford, there was room in the shop for only three customers at a time. When their new extension was opened by Sir William Haley on June 16 , three hundred guests browsed in traditional Blackwell fashion among the shelves, uncrowded and undisturbed. The new extension was christened the Norrington Room, after the president of Trinity College, under whose quadrangle Blackwells have found room to expand by digging a subterranean bookroom of enormous size.

Despite its size, and the need for artificial lighting, the room is prevented from seeming oppressive by the use of four different floor levels, and a variety of ceiling materials. There is shelving to carry 160,000 books, arranged to make the best use of space, and to break up the room into units of more human size. The expansion will enable Blackwells to carry even greater stocks on the premises, which is important in a service industry where orders must be dispatched as soon as possible. Although the personal shopper represents less than 10 per cent of the turnover, the increase in stock will also be a great convenience to him, particularly in science and technology, where the expansion is concentrated. A quick check in familiar fields confirmed that the increase in stock is quite genuine, which is good news for scientists both in Oxford and elsewhere. 